\title{
Ulnar Neuropathy Around the Mid-Arm Combined with Martin-Gruber Anastomosis
}

\author{
Bong Joo Kim, M.D., Dong Hwee Kim, M.D., Ph.D.
}

Department of Physical Medicine and Rehabilitation, College of Medicine, Korea University, Seoul 136-705, Korea

This study reports a rare case of ulnar neuropathy around the arm with Martin-Gruber anastomosis of a moderate conduction block in the forearm segment and a severe conduction block in the arm segment. Inching tests and ultrasonography showed a lesion between 12 and $14 \mathrm{~cm}$ from the medial epicondyle. It is concluded that axilla stimulation may provide diagnostic clues, and inching tests and ultrasonography may be helpful for localizing a lesion.

Key Words Martin-Gruber anastomosis, Ulnar nerve, Ultrasonography

\section{INTRODUCTION}

Although the most common entrapment site of the ulnar nerve is the elbow, it can be compressed at any location along its course. Ulnar neuropathy around the mid-arm may be caused by external pressure or by a medial intermuscular septum (the arcade of Struthers). ${ }^{1}$ Although Martin-Gruber anastomosis (MGA) accompanying ulnar neuropathy might not have clinical significance, unusual electrophysiologic findings, such as a conduction block in the forearm or elbow segment, might confuse diagnosis or prevent precise lesion localization. ${ }^{2,3}$ We report a case of ulnar neuropathy around the mid-arm with MGA, which demonstratesthe

Received June 20, 2011; Accepted October 17, 2011

Corresponding author: Dong Hwee Kim

Department of Physical Medicine and Rehabilitation, Korea University Ansan Hospital, 516, Gojan-dong, Danwon-gu, Ansan 425-707, Korea Tel: +82-31-412-5330, Fax: +82-31-412-5344, E-mail: rmkdh@korea.ac.kr (c) This is an open-access article distributed under the terms of the Creative Commons Attribution Non-Commercial License (http:// creativecommons.org/licenses/by-nc/3.0) which permits unrestricted noncommercial use, distribution, and reproduction in any medium, provided the original work is properly cited.

Copyright (c) 2012 by Korean Academy of Rehabilitation Medicine clinical importance of axilla stimulation in ulnar motor segmental nerve conduction studies, alongside the use of an ulnar nerve inching test and ultrasonography.

\section{CASE REPORT}

A 65-year-old man presented with a tingling sensation in the fourth and fifth digits of his left hand, which had developed after compression of the left arm by his body while in a drunken state some fourmonths previously. Touch sensation was reduced in the distributions of the left ulnar and dorsal ulnar sensory nerves. According to the Medical Research Council guidelines, the left abductor digiti minimi (ADM) and first dorsal interosseous (FDI) muscles were grade two, and thewrist (ulnar side) and finger flexions at the distal interphalangeal joints of the fourth and fifth digits were grade three. His other muscles were grade five. Froment's sign was positive on the left. The sensory nerve action potentials of the left ulnar digital branch and the dorsal ulnar cutaneous nerve were attenuated ( $13 \mathrm{uV}$ and $9 \mathrm{uV}$, respectively Table 1). Motor nerveconduction studies of the left ulnar nerve showed a 
Table 1. Sensory Nerve Conduction Studies

\begin{tabular}{|c|c|c|c|c|c|c|}
\hline \multicolumn{2}{|c|}{ Sensory } & \multirow{2}{*}{$\begin{array}{c}\text { Stimulation } \\
\text { site }\end{array}$} & \multirow{2}{*}{$\begin{array}{l}\text { Recording } \\
\text { site }\end{array}$} & \multicolumn{2}{|c|}{ Latency (msec) } & \multirow{2}{*}{$\begin{array}{l}\text { Amplitude } \\
\text { (uV) }\end{array}$} \\
\hline Side & Nerve & & & Onset & Peak & \\
\hline \multirow[t]{8}{*}{ Left } & Median & Wrist & III digit & 2.3 & 3.1 & 47 \\
\hline & & Palm & III digit & 1.2 & 1.8 & 52 \\
\hline & Ulnar & Wrist & V digit & 2.6 & 3.3 & 13 \\
\hline & & ME-3 & V digit & 5.8 & 6.6 & 9 \\
\hline & & $\mathrm{ME}+7$ & V digit & 7.6 & 8.4 & 4 \\
\hline & DUCN & Forearm & 4 th web & 1.8 & 2.3 & 9 \\
\hline & & ME-3 & 4th web & 4.6 & 5.2 & 7 \\
\hline & & $\mathrm{ME}+7$ & 4 th web & 6.3 & 6.8 & 5 \\
\hline \multirow[t]{6}{*}{ Right. } & Ulnar & Wrist & V digit & 2.3 & 3.0 & 33 \\
\hline & & ME-3 & V digit & 5.5 & 6.3 & 16 \\
\hline & & $\mathrm{ME}+7$ & V digit & 7.0 & 8.0 & 13 \\
\hline & DUCN & Forearm & 4 th web & 1.3 & 1.9 & 44 \\
\hline & & ME-3 & 4th web & 4.2 & 4.9 & 12 \\
\hline & & $\mathrm{ME}+7$ & 4 th web & 5.9 & 6.5 & 11 \\
\hline
\end{tabular}

DUCN: Dorsal ulnar cutaneous nerve, ME-3: $3 \mathrm{~cm}$ distal to medial epicondyle (ME), ME+7: $7 \mathrm{~cm}$ proximal to ME

significant conduction block ( $23 \%$ and $46 \%$, respectively) but normal conduction velocity $(56 \mathrm{~m} / \mathrm{s}$ and $54 \mathrm{~m} / \mathrm{s}$, respectively) in the forearm segment, nearly complete conduction block (85 and $100 \%$, respectively) and slow conduction velocity in the arm segment using ADM and FDI recordings (Table 2) (Fig. 1). Precise localization was assessed by inching technique in the arm, which demonstrated the lesion was between $13 \mathrm{~cm}$ and $14 \mathrm{~cm}$ from the ME in ADM recording and between $12 \mathrm{~cm}$ and $13 \mathrm{~cm}$ proximal to the ME in FDI recording (Table 3). Considering the significant conduction block and the normal conduction velocity in the elbow found in the left ulnar motor nerve conduction study, the presence of MAG could be suspected. To confirm this, the median nerve was stimulated with FDI muscle recording, and significant waveforms of compound muscle action potentials (CMAPs) were produced by stimulation of the left median nerve at the elbow, not at the wrist, confirming MGA (Fig. 2). Similar findings were observed in the right side (Fig. 2). The right ulnar motor nerve conduction studies with ADM and FDI recordings demonstrated partial conduction block (20 and $46 \%$, respectively) but normal conduction velocity only in the forearm segment, which indicated the presence of MAG. In the left forearm and the hand intrinsic muscles innervated by the ulnar nerve, abnormal spontaneous activities and/or polyphasic motor unit action potentials with markedly reduced recruitment were demonstrated (Table 4). Ultrasonography of the left ulnar nerve was performed to assess morphologic change of the ulnar nerve itself or the space-occupying lesions around it in the lesion site, based on electrodiagnostic examination, which revealed mild compression $\left(0.11 \mathrm{~cm}^{2}\right)$ at $12 \mathrm{~cm}$ and swelling $\left(0.18 \mathrm{~cm}^{2}\right)$ at $13 \mathrm{~cm}$ proximal to the ME (Fig. 3). Surgical exploration was recommended but conservative management (medication and physical therapy) was undertaken because of the patient's refusal of surgery.

\section{DISCUSSION}

To the best of our knowledge, this is the first reported case of proximal ulnar neuropathy in the mid-arm with MGA. This condition requires ulnar motor segmental studyincluding axilla stimulation, which may not be included in routine conduction studies. Thiscase showed definite conduction block in the left upper arm segment, using axilla stimulation of the ulnar nerve. In addition, CMAP in the proximal forearm was significantly reduced, compared with that of wrist stimulation. Based on the significant waveform of CMAP with median nerve stimulation at the elbow, the amplitude drop may be 
Table 2. Motor Nerve Conduction Studies

\begin{tabular}{|c|c|c|c|c|c|c|}
\hline \multicolumn{2}{|c|}{ Motor } & \multirow{2}{*}{$\begin{array}{c}\text { Stimulation } \\
\text { Site }\end{array}$} & \multirow{2}{*}{$\begin{array}{c}\text { Recording } \\
\text { site }\end{array}$} & \multirow{2}{*}{$\begin{array}{l}\text { Latency } \\
\text { (msec) }\end{array}$} & \multirow{2}{*}{$\begin{array}{l}\text { Amplitude } \\
\text { (mV) }\end{array}$} & \multirow{2}{*}{$\begin{array}{c}\text { Conduction } \\
\text { velocity }\end{array}$} \\
\hline Side & Nerve & & & & & \\
\hline \multirow[t]{10}{*}{ Left. } & Median & Wrist & APB & 3.3 & 12.1 & 56 \\
\hline & & Elbow & $\mathrm{APB}$ & 7.3 & 11.5 & \\
\hline & Ulnar & Wrist & $\mathrm{ADM}$ & 3.2 & 8.3 & 61 \\
\hline & & ME-3 & $\mathrm{ADM}$ & 6.4 & 6.4 & 53 \\
\hline & & $\mathrm{ME}+7$ & $\mathrm{ADM}$ & 8.3 & 6.2 & 22 \\
\hline & & $\mathrm{ME}+17$ & $\mathrm{ADM}$ & 12.9 & 0.9 & \\
\hline & Ulnar & Wrist & FDI & 3.8 & 13.0 & 54 \\
\hline & & ME-3 & FDI & 7.4 & 7.0 & 53 \\
\hline & & $\mathrm{ME}+7$ & FDI & 9.3 & 6.8 & - \\
\hline & & $\mathrm{ME}+17$ & FDI & & NR & \\
\hline \multirow[t]{10}{*}{ Right. } & Median & Wrist & APB & 3.1 & 12.1 & 56 \\
\hline & & Elbow & $\mathrm{APB}$ & 7.1 & 11.1 & \\
\hline & Ulnar & Wrist & $\mathrm{ADM}$ & 2.7 & 10.7 & 65 \\
\hline & & ME-3 & $\mathrm{ADM}$ & 5.8 & 8.6 & 56 \\
\hline & & $\mathrm{ME}+7$ & $\mathrm{ADM}$ & 7.6 & 9.0 & 53 \\
\hline & & $\mathrm{ME}+17$ & $\mathrm{ADM}$ & 9.5 & 8.4 & \\
\hline & Ulnar & Wrist & FDI & 3.7 & 16.4 & 65 \\
\hline & & ME-3 & FDI & 6.8 & 8.9 & 53 \\
\hline & & $\mathrm{ME}+7$ & FDI & 8.7 & 8.5 & 56 \\
\hline & & $\mathrm{ME}+17$ & FDI & 10.5 & 8.3 & \\
\hline
\end{tabular}

ADM: Abductor digiti minimi muscle, ME-3: $3 \mathrm{~cm}$ distal to medial epicondyle (ME), $\mathrm{ME}+7: 7 \mathrm{~cm}$ proximal to $\mathrm{ME}$, $\mathrm{ME}+17: 17 \mathrm{~cm}$ proximal to ME, APB: Abductor pollicis brevis muscle, FDI: First dorsal interosseous muscle, NR: No response

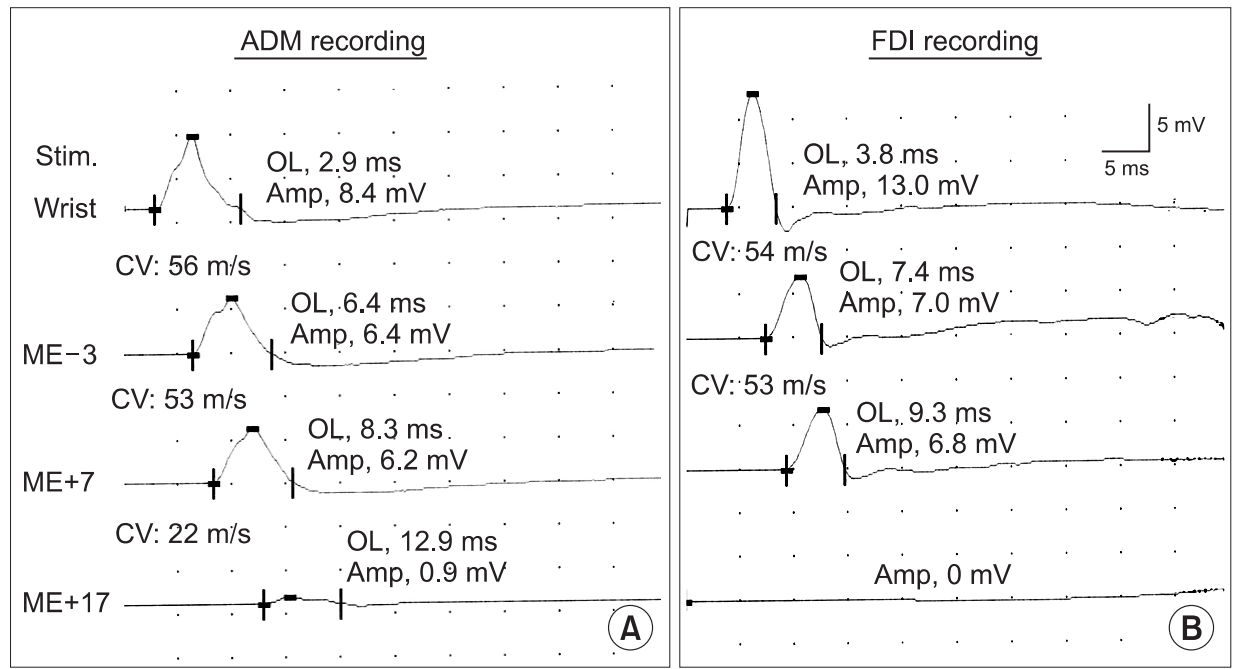

Fig. 1. Ulnar motor segmental study findings for the left ulnar motor nerve showing a mild to moderate pseudoconduction block in the forearm segment and a severe conduction block in the arm segment: (A) abductor digiti minimi (ADM) recording; (B) first dorsal interosseous (FDI) recording. Stim: stimulation sites, ME-3: $3 \mathrm{~cm}$ distal to the medial epicondyle (ME), ME $+7: 7 \mathrm{~cm}$ proximal to the $\mathrm{ME}, \mathrm{ME}+17: 17 \mathrm{~cm}$ proximal to the ME. considered to be pseudo-conduction block due to MGA.

The existence of MGA has been studied anatomically and electrophysiologically, bothin cadavers and healthy subjects. MGA may be classified into three types by crossover fiber terminations, or into two types based on anatomic branch numbers. ${ }^{4-8}$ During routine ulnar motor 


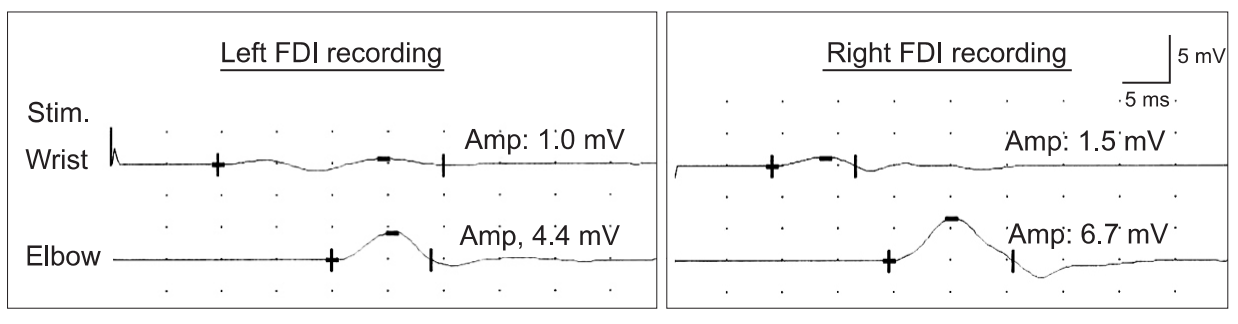

Fig. 2. Recording of the median compound muscle action potential of the first dorsal interosseous (FDI) muscle, showing increased amplitude for elbow stimulation on both sides. Stim: stimulation sites, Amp: amplitude.

Table 3. Inching Tests of the Left Ulnar Motor Nerve with Abductor Digiti Minimi and First Dorsal Interosseous Muscles

\begin{tabular}{cccccc}
\hline \multicolumn{2}{c}{ Inching test (motor) } & \multirow{2}{*}{ Stimulation site } & Recording site & Latency (msec) & Amplitude (mV) \\
\hline Side & Nerve & & & & \\
\hline Left & Ulnar & ME+16 & ADM & 11.0 & 1.3 \\
& & ME+15 & ADM & 10.8 & 1.0 \\
& ME+14 & ADM & 10.4 & 1.3 \\
& ME+13 & ADM & 9.2 & 6.3 \\
& ME+12 & ADM & 8.9 & 6.5 \\
& ME+11 & ADM & 8.8 & 6.3 \\
& ME+10 & ADM & 8.6 & 6.5 \\
& ME+16 & FDI & & NR \\
& ME+15 & FDI & & NR \\
& ME+14 & FDI & & NR \\
& ME+13 & FDI & & 5.4 \\
& ME+12 & FDI & 10.7 & 6.2 \\
\hline
\end{tabular}

ADM: Abductor digiti minimi muscle, FDI: First dorsal interosseous muscle, ME: Medial epicondyle, ME+10: $10 \mathrm{~cm}$ proximal to medial epicondyle (ME), ME+11: $11 \mathrm{~cm}$ proximal to $\mathrm{ME}, \mathrm{ME}+12: 12 \mathrm{~cm}$ proximal to $\mathrm{ME}, \mathrm{ME}+13: 13 \mathrm{~cm}$ proximal to $\mathrm{ME}, \mathrm{ME}+14: 14 \mathrm{~cm}$ proximal to $\mathrm{ME}, \mathrm{ME}+15: 15 \mathrm{~cm}$ proximal to $\mathrm{ME}, \mathrm{ME}+16: 16 \mathrm{~cm}$ proximal to ME, NR: no response

Table 4. Needle Electromyographic Examinations

\begin{tabular}{|c|c|c|c|c|c|c|c|c|}
\hline & \multirow{2}{*}{ Muscle } & \multirow{2}{*}{$\begin{array}{c}\text { Insertional } \\
\text { activities }\end{array}$} & \multirow{2}{*}{$\begin{array}{l}\text { Spontaneous } \\
\text { activities }\end{array}$} & \multicolumn{4}{|c|}{ Motor unit action potentials } & \multirow{2}{*}{ Recruit. } \\
\hline & & & & Normal & Polyphasic & Amp. & Dura. & \\
\hline \multirow[t]{6}{*}{ Left } & FCU & & $\mathrm{F} \& \mathrm{P}(+)$ & & Polys & & & 2-3 MUAPs \\
\hline & FDP III \& IV & $\mathrm{N}$ & - & & Inc. Polys & & & $\mathrm{R}$ \\
\hline & $\mathrm{ADM}$ & & $\mathrm{F} \& \mathrm{P}(+)$ & & Polys & & & 2 MUAPs \\
\hline & FDI & $\mathrm{N}$ & - & & Inc. Polys & & & $\mathrm{R}$ \\
\hline & $\mathrm{PT}$ & $\mathrm{N}$ & - & $\mathrm{N}$ & & & & $\mathrm{F}$ \\
\hline & EDC & $\mathrm{N}$ & - & $\mathrm{N}$ & & & & $\mathrm{F}$ \\
\hline
\end{tabular}

ADM: Abductor digiti minimi muscle, EDC: Extensor digitorium communi, F: Full, F\&P: Fibrillation potentials \& positive sharp waves, FCU: Flexor carpi ulnaris, FDI: First dorsal interosseous muscle, FDP III \& IV: Flexor digitorium profundus III \& IV, Inc.: Increased, MUAP: Motor unit action potential, N: Normal, R: Reduced, Polys: Polyphasic motor units, PT: Pronator teres 

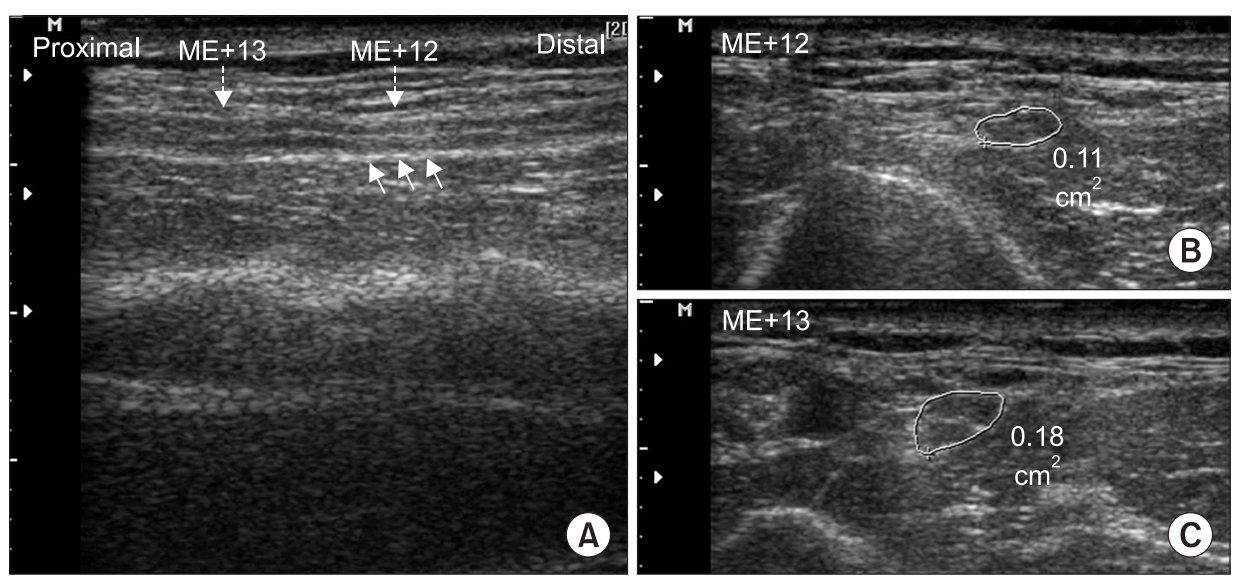

Fig. 3. Ultrasonograms showing mild compression (small arrows, $0.11 \mathrm{~cm}^{2}$ ) of the ulnar nerve at $12 \mathrm{~cm}$ proximal to the medial epicondyle $(\mathrm{ME}+12)$, and mild swelling $(0.18$ $\left.\mathrm{cm}^{2}\right) 13 \mathrm{~cm}$ proximal to the medial epicondyle (ME+13). (A) longitudinal section, (B) cross-section at $\mathrm{ME}+12$, (C) cross-section at ME+13.

NCS, if an amplitude drop without conduction slowing is observed in the forearm or elbow segment, MGA may be suspected, ${ }^{3}$ and even when ulnar neuropathy at the elbow is diagnosed based on electrophysiologic test findings, MGA might accompany ulnar neuropathy at the elbow. This suggests that MGA screening might be important in UNE patients. ${ }^{2}$ Usually, MGA is not of clinical significance, but in cases of complete UNE with MGA, clinical findings of complete UNE may not be severe, depending on the degree of MGA. ${ }^{9}$ To prove the existence of MGA, ADM or FDI, recordings of median nerve stimulation at the wrist and elbow are necessary, and a CMAP with elbow stimulation (with a larger amplitude than that observed for wrist stimulation) should be observed. In our case, this anastomosis of both extremities was confirmed by FDI recordings of median nerve elbow stimulation.

Ultrasonography is very useful for evaluating the structural appearance of nerves and the appearance of surrounding structures in cases of entrapment neuropathy. In particular, the diagnostic usefulness of ultrasonography might be increased and its value in evaluating focal neuropathy might be maximized when used in combination with electrodiagnostic results. In our case study, a combination of electrodiagnostic and ultrasonographic findings accurately located the lesion site and demonstrated morphologic change of the ulnar nerve, even though this was minimal.

In conclusion, arm segment studies of the ulnar nerve may be useful for detecting and differentiating proximal lesions of the ulnar nerve stemming from anatomic variations such as MGA. Furthermore, inching tests and ultrasonography around the arm may be helpful in terms of localizing lesion sites and evaluating morphologic changes in the nerve or its surrounding structures.

\section{REFERENCES}

1. Dawson DM, Hallett M, Wilbourn AJ. Entrapment neuropathies, 3rd ed, Philadelphia: Lippincott-Raven, 1999, 134-135

2. Whitaker $\mathrm{CH}$, Felice KJ. Apparent conduction block in patients with ulnar neuropathy at the elbow and proximal Martin-Gruber anastomosis. Muscle Nerve 2004; 30: 808-811

3. Marras C, Midroni G. Proximal Martin-Gruber anastomosis mimicking ulnar neuropathy at the elbow. Muscle Nerve 1999; 22: 1132-1135

4. Stewart JD. Focal peripheral neuropathies, 4th ed, Vancouver: JBJ Publishing, 2010, 196-198

5. Amoiridis G, Vlachonikolis IG. Verification of the median-to-ulnar and ulnar-to-median nerve motor fiber anastomosis in the forearm: an electrophysiological study. Clin Neurophysiol 2003; 114: 94-98

6. Lee KS, Oh CS, Chung IH, Sunwoo IN. An anatomic study of the Martin-Gruber anastomosis: electrodiagnostic implications. Muscle Nerve 2005; 31: 95-97

7. Erdem HR, Ergun S, Erturk C, Ozel S. Electrophysiological evaluation of the incidence ofmartin-gruber anastomosis in healthy subjects. Yonsei Med J 2002; 43: 291-295

8. Rodriguez-Niedenfuhr M, Vazquez T, Parkin I, Logan B, Sanudo JR. Martin-Gruber anastomosis revisited. Clin Anat 2002; 15: 129-134

9. Kim DH, Kang YK, Hwang MR, Jo HS. Martin-Gruber anastomosis in ulnar neuropathy around the elbow. J Korean EMG Electrodiagn Med 2002; 4: 97-100 